\title{
ABSTRAÇÃO E SISTEMATIZAÇÃO NA IURISPRUDENTIA ROMANA
}

\author{
Dárcio Roberto Martins Rodrigues \\ Professor Doutor do Departamento de Direito Civil \\ da Faculdade de Direito da Universidade de São Paulo
}

Resumo:

O presente ensaio é um breve panorama da lenta evolução da Iurisprudentia romana em direção a um grau mais elevado de abstração e sistematização.

Abstract:

In this essay the author presents a bird's eye view of the gradual evolution of ancient Roman legal science toward a higher degree of abstraction and systematization.

Unitermos: Jurisprudência romana; método casuístico; processo de abstração; emprego das distinctiones; dialética grega.

\section{Introdução.}

Quando se fala na Iurisprudentia romana, sói-se, com acerto, salientar antes de mais nada, que esse termo tinha para os romanos um significado bem distinto daquele que hoje damos a ele. De fato, jurisprudência não era entendida como um conjunto de soluções reiteradas de um órgão jurisdicional - como a definimos hoje mas sim como o resultado da interpretatio iuris praticada pelos cultores do Direito, os jurisconsultos. Era, no dizer de W. Kunkel' um verdadeiro "Juristenrecht", um "direito de juristas" emanado exclusivamente dos responsa ou da produção literária dos iurisprudentes, independentemente da atividade judicial dos magistrados ou da legislação formal. ${ }^{2}$

O equívoco, entanto, está em dizer, simplesmente, que a Iurisprudentic corresponderia à doutrina (no sentido que modernamente se dá à palavra), ou, pior ainda, em afirmar, muito simplesmente, que ela poderia ser entendida como o "direito científico". ou como uma "ciência do direito" Trata-se, é claro, de um grave exagero. Em primeiro lugar, pelo emprego abusivo da palavra "ciência" nesse contexto. É evidentc

I. Römische Rechtrgeschichte, 12. ed, Köln, Bohlau, 1990, pp. I15-116.

2. É verdade que parte expressiva da obra dos jurisconsultos romanos se constitui de comentários ad edictum, e está claro que a interpretutio também se aplicava a leis e senatusconsultos, e não apenas ao iut: civile antigo ou aos mores muiorum. Entretanto, W. Kunkel (cit. nota ih I supra) ressalta que em seu sentido mais estrito, lurisprudentia era o resultado da pura criação doutrinária, e com certeza foi nesse sentido que o "Jurisrenrech" constituía a mais importante fonte de produção do Direito Romano. 
que ciência, entendida como um sistema organizado de conhecimentos adquiridos e coordenados consoante uma metodologia que chamamos de "científica" - em sentido cartesiano -, sem dúvida é uma idéia definitivamente alheia ao pensar do jurista romano.

Certamente é bem conhecida a clássica defïnição de Ulpiano (Ulp I inst D. 1,1,4), segundo a qual "iurisprudentia est divinarum atque humanarun rerum notitia, iusti atque iniusti scientia" (a Jurisprudência é o conhecimanto das coisas divinas e humanas, a noção do justo e do injusto). Há que se pôr tento, porém, ao fato de que a palavra scientia em latim não tinha, evidentemente, o sentido hodierno de ciência, podendo ser traduzida simplesmente por "conhecimento" de acordo com a própria etimologia da palavra, que se liga ao verbo scire (saber, conhecer). Por outro lado, a invocação da "humanarum atque divinarum rerum notitia" torna patente que a Jurisprudência era muito mais o resultado da aplicação do bom-senso e da experiência humana vivida, temperada pelo sentimento ético e de eqüidade ("iusti atque iniusti scientia") $)^{3}$ do que do simples emprego de uma técnica "científica" de busca de respostas a questões teóricas. O vocábulo prudentia (presente no composto iurisprudentia), por outro lado, provém de pro + videre, literalmente "conhecer de antemão"; donde o prudens é aquele que age "com conhecimento de causa"; o que leva a palavra prudentia a significar muito mais sabedoria do que conhecimento científico. ${ }^{4}$

3. Não nos escapa que iustus liga-se etimologicamente a ius, e portanto significa apenas "conforme o ius", ou seja, "fundado no direito"; a idéia de "justo", como a entendemos hoje, seria mais propriamente expressa em latim pelo vocábulo cequus. É evidente, porém, que o sentimento ético de Justiça não era c nem poderia ser de todo alheio ao sentido romano de iustus. Ademais, já indicam $\mathrm{H}$. Heumann e E. Seckel (Handlexikon zu den Quellen des römischen Rechts, $9^{2}$ ed., Jena, Gustav Fischer, 1926.) que, entre as demais acepções, o termo iustus admite a de "gerecht handelnd", o que é referendado nas lontes por expressões como "iudex iustus." (Ulp. 25 ad. ed. D. 11,7,14,13 - texto deveras interessante, porquanto o jurisconsulto afirına ser próprio do index iustus. decidir mais livremente, "solumius.", e sempre " "ıéquitulem sequi") ou "iustius facere" (Pap. 3 Quaest. D. 28,6,12). Entretanto, adentrar em maiores digressōes filosóficas acerca do conceito romano de Justiça, ou filológicas sobre o emprego e semântica desses vocábulos, em muito extrapolaria o modesto escopo deste nosso trabalho.

4. Acerca dessas etimologias, A. Walde- J. B. Hoffinann, Lateinisches Etymologisches Wörterbuch. 5 ed., Heidelberg, Carl Winter, 1972; A. Ernout - A. Meillet, Dictionnaire Etymolongique de la Lingue Latine Paris, Klincksieck, 3.ed., 195I; e tanbém F. Martin, Les Mots Latins, Paris, Hachette, 1976. Quanto à acepção exata de prudens, H. Menge, (Lateinische Synonimik, 7. ed., Heidelberg, Carl Winter Universitätsbuchhandlung, 1988) traduz por "umsichtig, (welt)klug", ressaltando a conotação de um conhecimento mundano, de uına experiência vivida ("im praktischen Leben erfahtren, wer die vorliegende Verhältnisse gewandt und sicher zu behandeln weiß"); em oposição, a idéia de uma ciência era expressa por termos como doctrina, disciplina, ars; nunca se usava scientia para designar uma disciplina científica, mas sim o conhecimento subjetivo que uma pessoa tem, de um modo geral ("die erlangte Kenntnis als Summe dessen, was einer weiß oder versteht") - o que pode incluir também, mas não exclusivamente, o conhecimento científico. O termo notitia, que igualınente aparece na definição de Ulpiano, signilicava também conhecimento, mas já no sentido de informação, de estar ciente ou informado de alguma coisa ("die Bekanntschaft mil, das Wissen um etwas"). O baralhamento desses termos numna tradução desavisada poderá levar o exegeta das fontes romanas a conclusões inuito distantes da verdade, como entender que os romanos julgassem possível ter conhecimento "científico" (no sentido moderno, cartesianio) das coisas do espírito ("humanarum atque divinarum rerum") ou do universo ético ("iusti atque iniusti"). 
Tampouco convém a noção de doutrina para explicar a Iurisprudentic dos romanos. Os jurisconsultos clássicos não criavam doutrina, no sentido de estabelecerem um sistema lógico e coordenado de conceitos abstratos, como o faz a civilística moderna. Uma "Begriffsjurisprudenz" (Jurisprudência de conceitos), tal como foi admiravelmente praticada pela pandectística do século XIX, distancia-se muito do pensamento jurisprudencial clássico, ou mesmo se opõe por completo a ele. É sabido que jamais interessou aos romanos formula conceitos teóricos ou desenvolver sistemas para explicar os fenômenos jurídicos.

Outro aspecto que desperta a atenção é o método estritamente casuístico da Jurisprudência romana. O jurista romano nunca pensava no Direito como um sistema de institutos abstratos, não pensava no todo ordenado: pensava sempre no caso prático, na congérie de situações particulares, cada uma delas merecendo ums solução individual - e no entanto, em vez de conduzir a um conjunto de decisōẹs arbitrárias, tal metodologia permitiu o desenvolvimento de uma ordem jurídica notavelmente coesa.

Diante disso, torna-se grande o interesse em indagar de que forma operava o pensar dogmático dos jurisprudentes romanos, o qual como vimos não correspondia nem ao conceito moderno de ciência nem ao de doutrina. Maior se torna a relevância do assunto quanto se tem em vista que o Direito Romano constitui um admirável monumento de conceitos jurídicos perfeitamente harmônicos e solidamente coerentes. De que forma foi possível - por paradoxal que pareça - erigir um sistema tão perfeito sem adotar nenhuma sistentática? Ou, rectius, como conseguiram fazer funcionar com a perfeição de um sistema um conhecimento jurídico organizado de forma assistemática?

Sabemos que o tema é delicado e complexo, tendo já merecido a atenção de grandes estudiosos do presente e do passado. Não é nosso intento apresentar um estudo exaustivo de tão complexa matéria, nem mesmo acrescentar algo de revolucionariamente novo ou original, mas tão-somente oferecer algumas ponderações acerca do método do pensamento jurisprudencial romano na formação de suas regras $\mathrm{e}$ conceitos teóricos. Visamos, destarte, chegar mais próximos, não já de uma total elucidação, mas ao menos de uma boa compreensão das questões fundamentais que envolvem o problema em tela.

II. A Gênese de uma "Ciência" do Direito.

A formulação de princípios gerais, conceitos técnico-jurídicos ou regras de Direito é o resultado de um processo de abstração que parte do singular para o genérico, isto é, da solução de um problema caso a caso para a indução de um conceito geral presente no substrato de cada uma das soluções individuais, abstraídas de seus elementos acidentais. F. Schulz $z^{5}$ exemplifica esse processo partindo de uma primeira

5. Prinzipien des römischen Rechts, München, Duncker \& Humbolt, 1934. (reimpr. Berlin, Duncker \& Humbolt, 1954), p. 27 e ss). 
hipótese em que se estabelecesse a responsabilidade do vendedor de um cavalo pelo prejuízo causado em razão do atraso na entrega do mesmo. Dessa decisão isolada, e em face de uma pluralidade de situações análogas, poder-se-ia transitar para um primeiro grau de abstração e concluir que o vendedor de um animal qualquer (e não apenas de um cavalo) será responsável pelo atraso na entrega ao comprador. Ainda segundo $F$. Schulz, esse passo inicial em direção à generalização já estaria presente nos primeiros documentos jurídicos de que temos notícia, como o Código de Hamurabi, o Pentateuco e mesmo a Lei das XII Tábuas.

Em um momento seguinte, seria atingido um segundo grau de abstração com a extensão do mesmo princípio a todo e qualquei vendedor, e não-somente aos vendedores de animais. $O$ estágio seguinte seria alcançado quando houvesse o reconhecimento de que não apenas o vendedor, mas todo devedor em uma relação contratual deveria estar sujeito à mesma responsabilidade. Finalmente, o grau superior de abstração viria ao se verificar que o atraso no adimplemento nada mais é do que uma das inúmeras maneiras possíveis de violação do direito de crédito, resultando daí o princípio ou regra geral da responsabilidade contratual: o devedor está obrigado a indenizar o credor por qualquer prejuízo decorrente do não-cumprimento de uma obrigação contratual.

Os romanos, como é sabido, foram de um modo geral infensos a abstrações e conceitos gerais. O que as fontes romanas nos fornecem são, sobreludo. coletâneas de casos práticos e pareceres, pouco pródigos em normas de apliciação generalizada. Até os institutos fundamentais do Direito Privado, como dominitum, possessio, contractus etc., ficaram sem uma definição perfeita e abstrata." E mesmo quando os jurisconsultos romanos permitiam-se a enunciação de regras de Dircito, jamais ousavam afastar-se demasiado da concretude da casuística, valendo-se de exemplos práticos para fundamentar suas idéias. No dizer de L. Wenger, ${ }^{7}$ a Jurisprudência romana gostava sempre de manter os dois pés no chão.

Não foi por outra razão, diga-se de passagem, que a própria idéia de lei, entendida como declaração geral de direito estatuída pelo Estado, era muito pouco prestigiada no ordenamento jurídico romano. ${ }^{\text {}}$ De fato, durante todo o período clássico

6. Dizia Javoleno: "Omnis definitio in iure civili periculosa est: partum est enim, ut non subrerti possit." (Iav. I/ epist. D. 50, 17,202): "Toda definnição no direito civil é perigosa: pois quase nada impede que seja subvertida".

7. Die Quellen des römischen Rechts, Wien, Holzhausens, 1953, p. 487, nota 150.

8. Com isto pretendemos dizer apenas que a elas foi atribuída diminuta relevância prática, quando confrontadas com outras fontes do Direito, quais a lurisprudentia ou os edicta dos magistrados. Nĩo se entenda, contudo, que às leges faltasse prestígio no sentido de respeito e autoridade. Ao contrário, sendo a lex a manifestação da vontade legiferante do próprio populus romanuıs, era ela o verdadeiro protótipo da fonte do Direito, e servia de parâmetro e modelo para a força vinculante das demais; Gaio, por exemplo, aproxima das leis os plebiscitos, senatusconsultos, constituições imperiais e ressponsus prudentutum ao dizer que estes "legis vicem optinent" (Gai. 1, 3-7). Nesse sentido M.Kaser,Zur Problematik der Rechtisquellenlehre, in Römische Rechtsquellen und angewandhe Juristemmethode, Wien-Köln, Böhlau, 1986, p. 14 e ss. 
virtualmente não existiu regulamentação estatal atinente às áreas centrais do Direito Privado, tais como a propriedade, os contratos, o matrimônio ou a sucessão hereditária." No Direito Romano clássico, a principal forma de expressão do Direito era a atividade prática dos jurisconsultos e pretores, que corrigiam e integravam o antigo ius civile de acordo com as necessidades sociais. Mas a lex, proposta pelo magistrado e volada pelos comícios populares, tinha caráter sempre excepcional, sendo utilizada apenas para os casos em que era indispensável a objetivação de uma norma geral (e.g. para quantificaro valor de uma indenização, como por exemplo no caso da iniuria). Durante cerca de 500 anos de atuação dessa fonte produtora de Direito (ou seja, do final do século VI a.C. até o início do principado), os estudiosos costumam enumerar não mais de cerca de 800 legesi ${ }^{10}{ }^{10}$ a maioria delas para fïns de organização estatal ou regulamentar algum detalhe de utilidade prática econômica e social" - quantidade irrisória, diante da pletora de leis e decretos que vemos hoje despejados nos diários oficiais a cada dia.

O que mais espanta é que o desinteresse pela teorização e pela abstração era tão grande, que faltam até mesmo no latim jurídico clássico expressões técnicas para designar conceitos que hoje, com o modo de pensar do jurista moderno, são vistos como elementos basilares do direito, tais como o de capacidade jurídica, sujeito de direitos ou ato jurídico. Até mesmo noções menos abstratas, mais concretamente ligadas a um interesse prático, dificilmente eram formalizadas em teoria. Falava-se, por exemplo, em actiones in rem e actiones in personam, sem contudo chegar a uma idéia - e muito menos a uma palavra - para direitos reais $\mathrm{c}$ direitos obrigacionais. ${ }^{12}$

Não-obstante, houve um momento na história da Jurisprudência romana no qual se observa, ao invés dessa aversão por generalizações, o surgimento de uma

9. "Das 'Volk des Rechts' ist nicht das Volk des Gesetzes", já observou F. Schulz Prinzipien..., (cit. supra nota lh 5) pag. 4.

10. Para estudos a este respeito, é de importância fundamental o trabalho de G. Rotondi, que executou uma exaustiva pesquisa, arrolando-as uma a uma em ordem cronológica. Ver o seu verbete Comicialis Lex, na Enciclopedia Gituridica Italiana (posteriormente publicado em forma de livro sob o título Leges. Publicae Populi Romani, Hildesheim, Olıns, 1962).

11. O ınesıno se pode dizer dos senutuscon.sulta e mesmo das comstitutiones principum, que tambémn eram normas gerais.

12. A inexistência de um termo técnico para expressar tais conceitos não signilíca que eles não pudessem em muitos casos ser inferidos intuitivamente e tacitamente admitidos de maneira indireta, não formalizada. Por exemplo, não se chegou nunca a uma distinção teórica entre os negócios translativos de direitos (como a mancipatio ou a in iure cessio) e os meramente geradores de relações jurídicas pessoais (como o contrato de compra e venda), semelhante noção não chegou a ser formulada. Na prática, porém, a diferenciação era feita de maneira cristalina e meridiana. Note-se por exemplo com que zelo os romanos insistiam na distinçāo entre a dotis dictio e a dotis datio. (A essse respeito, ver K. Ayiter, Systematisches Denken und Theorie im römischen Recht, in Studi in onore di Arnaldo Biscardi I, Milano. Cisalpino Goliardica, 1981, pp. 9 e ss.). 
corrente doutrinária com manifesto pendor para a teorização e a criação de regulae abstratas. Foi o período da chamada "jurisprudência regular" ("Regularjurisprudenz", nome que lhe foi dado pela romanística moderna ${ }^{13}$ ), que assinalou o início da elaboração científica do direito em Roma. A partir dos responsa a diversos casos concretos, começava a emergir a idéia unificadora que servira de embasamento a cada um deles, elevando gradativamente o pensamento jurídico da pura casuística empírica para uma abordagem teórica, ainda que incipiente, do fenômeno jurídico. Foi um processo lento, é verdade, mas, no fraseado peculiar de L. Wenger, estava escancarado o portão da mera práxis para a ciência ${ }^{14}$ Teria sido esse, então, o período mais fértil para a criação das regulae iuris, muitas das quais se perpetuariam nos textos dos jurisconsultos clássicos e, posteriormente, na compilação de Justiniano, sobretudo no último título do Digesto (D. 50,17 "De Diversis Regulis Iuris Antiquis").

Muito se tem debatido na doutrina acerca da determinação precisa da época em que teria tido início essa tendệncia na Jurisprudência republicana romana. De acordo com a controversa teoria de P. Jörs ${ }^{15}$ o precursor teria sido Marco Pórcio Catão (234 - 149 a.C. $)^{16}$ fïlho de Catão, o censor. Teria sido ele o primeiro a afastar o métode puramente casuístico a fïm de buscar na analogia entre casos, responsa e legis actiones semelhantes um novo elemento para a decisão de casos futuros: as regulac iuris. Daí o chamar-se esse período de "jurisprudência regular" Contestando essa idéia, E. Gandolfo"7 após afirmar que os passos do Digesto em que Jörs se estriba para corroborar sua tese não são conclusivos, insiste em que a Jurisprudência romana desde as XII tábuas sempre fora "regular" demonstrando a existência de regras précatonianas, que se referem a institutos do Direito antigo. Poder-se-ia a isto replicar que o próprio Jörs não negava que já Catão pai e outros antes dele houvessem cunhado

13. Cf. e. g. G. Dulckeit - F. Schwarz - W. Waldstein, Römische Rechstgeschichte, 4 ed., München, Beck, 1989, p. 167 e ss.

14. Die Quellen... (cit. supra nota 7), p. 487.

15. Römische Rechtswissenschuft zur Zeit der Republik, Berlin, Müller, 1888. Contra esse autor: E. Gandolfo, Catone e le Regole di Diritto, in Archivo Giuridico, v. 43, p. 409 e ss. Uin detal hado escorço de ambas as argumentações está em G. Cervi, Regole di Diritto (Regullue luris), verbete na Enciclopedia Giuridica Italiana. Cervi, no entanto, acolhe a tese de Gandolfo.

16. Seu nome está ligado à chamada "regula Catoniunc", uma das mais antigas regulae iuris, contida no título D. 34,7, cujo primeiro fragmento (Cels. 35 dig) enuncia: "Catoniana regula sic definit. quod, si testamenti facti tempore decessisset testator; inutile foret, id legatum quandoctumatue decesserit, nom valere. ("A regra catomiana assim define: sendo mulo am legado na hipótese de que o testador morresse no momento em que o testamento estivesse sendo feito, entäo aquele le gado näo tercí validade, seja cyuando for que o testudor morra"). Como se vê, originalmente se referia apenas aos legados, mas em $P$ (uul 8 ad Sab.D. 50,17,29, Paulo exprime a mesma regra em termos gerais: "Quod initio vitiosum est non potest tractu temporis comvalescere" ("aguilo que já está viciado no seu inicio näo pode convalescer com o decurso do tempo").

17. Citado supra, nota $\backslash \mathrm{h} 15$. 
regras jurídicas, mas que, como propugna L. Wenger ${ }^{18}$ o mérito de Catão fillho foi o de por primeiro trabalhar essas regras de modo sistemático, dando-lhes uma forma literária própria e transformando-as $\mathrm{cm}$ ponto de partida das discussões tanto de casos práticos quanto do próprio conteúdo do Direito aplicável.

Não interessa, todavia, para os fïns do presente estudo, adentrar na discussão deste ponto, nem examinar com maior vagar os argumentos de uma ou outra parte. Parece-nos, em verdade, de somenos importância contender acerca do momento histórico em que ocorreu essa transformação ou das razões para atribuir os louros a este ou àquele personagem. Releva, na ordem destas ponderações, compreender o processo mesmo da evolução do pensar jurídico que conduziu à gênese das regulae iuris.

Não há negar que os dois últimos séculos da República romana foram da maior relevância para o desenvolvimento da Jurisprudência como verdadeira ciência (se é que se pode usar esta expressão com relação ao Direito Romano; cf. supra parte I). Refere-nos por exemplo Pompônio, em Pomp. l. s. enchir. D. 1,2,2,41, que Quinto Múcio (cônsul em 95 a.C., morto em 82 a.C.) foi o primeiro a expor sistematicamente ("generatim") todo o Direito Civil, o que já é, em si, um fato de grande signilicância. Ademais, sabe-se que a maior parte das regulae iuris provém do final da era republicana ${ }^{19}$. O que teria levado a Jurisprudência dessa época a alçar tais vôos, tão contrários à índole da cultura romana, à qual, conforme já apontamos, repugnavam o pensamento sistemático e as abstrações?

A resposta, no entender de F. Schulz ${ }^{20}$ estaria na influência grega exercida sobre as artes e ciências romanas, mormente após a segunda guerra púnica. É bem verdade, e não o nega F. Schulz, que essa influência marcante jamais deixou de existir, mas foi particularmente intensa no período indicado, quando floresceu o movimento intelectual que os historiadores chamam de helenismo.

Para F. Schulz, a contribuição delïnitiva do helenismo loi a introdução do pensamento dialético em Roma. Devemos aqui, é claro, entender a palavra dialética no seu sentido platônico, significando o estudo dos gêneros e das espécies, a buscá do conhecimento por meio da distinção (em grego dia...resij) por um lado e da síntese (gr. sun@gwg» ou sÚnqesij) por outro. Esse método de discernimento sistemálico dc gêneros e espécies arrancou os estudos jurídicos do torpor da casuística estéril, e levou os jurisprudentes de então a imitar os dialéticos gregos, procurando dividir em categorias distintas os vários institutos jurídicos.

O nome técnico para essas distinções era, em grego, como já foi dito, dia...resij, termo que corresponde em latim a divisio, differentia ou distinctio. Este

18. Die Quellen...,(cit. supra, nota th 7) p. 487, nota I5I.

19. Cf. S. Riccobono, Regulae luris, verbete no Novissimo Digesto Italiano, que apresenta uma interessante epítome deste tema. Mas v. (b. F. Schulz, Prinzipien... (cit. supra, nota \h .5), p. 33-37.

20. F. Schulz, History of Roman Legal Science, London, Oxford University Press, 1946, p. 60) e ss. 
último consagrou-se na Idade Média, a partir da Escola de Bolonha, e tornou-sc vocábulo técnico na terminologia dos glosadores. ${ }^{21}$

A importância do emprego das distinctiones pelos jurisconsultos romanos não pode ser subestimada. Foi o que permitiu, por exemplo, a sistematização do iuts civile por Quinto Múcio. O não dispormos de material suficiente para reconstitur sua obra é uma grande lástima para o estudo da história da Jurisprudência romana.

No Direito Clássico encontramos em estágio avançado a técnica de classificar por gêneros e espécies os institutos jurídicos, o que é conspícuo em Gaio, cujas institutas são uma exposição bastante metódica. Gaio distingue as espécies de pessoas (G. 1,9-12; G. I,48; G. I, I 42), de coisas (G. 2,2; G. 2, I2; G. 2, I 8), de heranças (G. 2,99), de legados (G. 2,192), de obrigações (G. 3,88-89), de ações (G. 4,1), c assim por diante. Muitas dessas distinções do período clássico remontam na verdade à fase anterior, e o próprio Gaio nos aponta algumas distinctiones republicanas (G. 1,188; G. 3,183, e.g.), fazendo mesmo referência a Quinto Múcio, cujas distinctiones ao que parece eram muito bem acolhidas e discutidas pelos jurisconsultos da República.

Foi a distinctio, portanto, uma contribuição fundamental da dialética, trazida pelo helenismo. Mas é certo que o uso de distinctiones traz em pós de si um outro fator determinante para os novos rumos do pensamento jurídico romano. Pois, diante da exposição sistemática de várias hipóteses que incorporam caracteres contrastantes contidos no substrato de um mesmo instituto, a aplicação do raciocínio dialético desperta no estudioso a aspiração de perquirir mais além, chegando às razões mesmas dessas distinções, aos seus princípios governantes. Se, pois, ao distinguir e.g. as várias formas de stipulatio (como em G. 3,103), for questionado o porquê de algumas delas serem reconhecidas como válidas e outras não, pode-se chegar a uma resposta abstrata, como fez Quinto Múcio em Muc.l. s. Órwn D. 50,17,73,4 : "Nec paciscendo, nec legem dicendo, nec stipulando quisquam alteri cavere potest" ou seja, ninguém pode, por ato seu, obrigar contratualmente a outrem. Outro exemplo: ao distinguir (como em Ulp. 2 inst. D. 8,3,1,pr.) as várias espécies de servidões rústicas, a observação de que o iter está contido no actus, mas não vice-versa, pede uma explicação geral, que o próprio Ulpiano deu em Ulp. 27 ad Sab. D. 50,17,21: "Non debet cui plus. licet quod minus est non licere" que é uma expressão do nosso brocardo "quem pode o mais, pode o menos". O importante é que a conclusão, em ambos os exemplos, enuncia um

21. E. Seckel (Distinctiones Glossatorum Graz, Akademische Druck und Verlagsanstalt, 1956, p. 281), assim conceitua a "distinctio" (tradução nossa do alemão): “" Distinctiomes' são produções literárias que operam com diferenças no interior de um conceito primário original. O conceito primário é decomposto ('distinguere') tanto quanto possível em seus conceitos secundários originais, por meio da atração de caracteres particulares contrastantes; conforme o caso, o conceito secundário submete-se ao mesmo procedimento científico ('subdistinguere'). Os conceitos primários a dissociar são buscados já no campo dos tipos legais ('Tutbestand'), já no das regras de direito, já no das relações jurídicas. Algumas das distinctiones' podem ser comparadas com os parágrafos dos nossos manuais teóricos altamente sistematizados". Saliente-se, entretanto, que Seckel aqui se refere mais específicamente ìs distinctiones dos glosadores, que thes deram emprego sistemático muito mais extensivo do que os romanos. 
princípio aplicável a um gênero mais amplo de situações, reunindo outros elementos além daqueles inicialmente visados. Quando os jurisconsultos aprenderam a raciocinar dessa forma, a Jurisprudência romana assistiu a um episódio marcante na sua evolução: o nascimento da "regula iuris"

A criação de uma regra de Direito consiste, então, no ato de extrair de um conjunto de casos análogos o princípio geral subjacente a todos. Um exemplo famoso, bem documentado pelas fontes, permite-nos acompanhar pelos textos romanos o caminho percorrido do fato à regra.

Valério Máximo, nos seus Factorum Dictorunque Memorabilium Libri IX, $(8,2,4)$, relata o seguinte sucesso:

\begin{abstract}
"Multus sermo eo etiam iudicio manavit, in quo quidan furti dannatus est, quod equo, cuius usus illi usque ad Ariciam commodatus fuerat, ulteriore eius municipii clivo vectus esset."

[Tradução Nossa: "Houve também muito falatório em razão daquele processo no qual alguém foi condenado por furto, porque foi $c$ com $\mathrm{um}$ cavalo, cujo uso lhe fora cedido em empréstimo até Arícia, a uma colina mais além daquele município."]
\end{abstract}

Trata-se de um acontecimento isolado, do qual o texto não pretende extrair ilação alguma, mesmo porque quem o relata não é jurista. Mas é de se inlerir que até então não havia uma opinião assente naquele sentido, pois que, segundo o cronista, a decisão causou "muito falatório"

Reencontramos o problema em um outro texto, este de Aulo Gélio (Noctes Atticae, 6,15), que nos dá notícia de caso semelhante, enriquecido pela alusão ao parecer de importantes jurisconsultos, inclusive Quinto Cévola:

"Labeo in libro de XII tabulis secundo acria et severa judicia de furtis habita esse apud veteres scripsit, idque Brutum solitum dicere, et furti damnatum esse, qui iumentum aliorsum duxerat quam utendum acceperat, item qui longius produxerat quam quo utendum in quem locum petierat. Itaque $Q$. Scaevola in librorum, quos de iure civile composuit, XVI verba haec posuit: quod cui servandum datum est, si is usus est, sive quod utendum accipit, ad aliam rem atque accipit usus est, furti se obligavit'." [Tradução Nossa: "Labeão, no segundo livro sobre as XII tábuas, escreveu que entre os antigos houve julgamentos enérgicos e severos acerca dos furtos, e que Bruto disse ser isso comum, e que aquele que conduzira um jumento a outro lugar que não aquele para o qual o recebera para uso, também foi condenado por furto, bem como quem prosseguira além do local até o qual havia pedido para usar. Do mesmo modo Quinto Cévola, no décimo-sexto dos livros que compôs acerca do direito civil, incluiu estas palavras: 'Se aquele, a quem algo foi dado 
para ser guardado, o usou, ou se usou para outra coisa que não aquela para a qual o recebeu, tornou-se responsável por furto.".]

Labeão, primeiro chete da escola proculiana, foi contemporâneo de Augusto. O Bruto a que ele faz menção deve ser Marco Júnio, jurisconsulto do século II a.C. Vê-se que com Bruto já se verilica um avanço no sentido da generalização, posto que este não faz menção a um acontecimento especílico, excepcional, como ocorre no texto de Valério Máximo, mas fala da hipótese de um jumento emprestado (e não mais um cavalo) e que tivesse sido levado não só além do local combinado, mas também, por extensão, a qualquer lugar diverso daquele. E Quinto Cévola por sua vez elabora uma primeira regra, aplicável a qualquer objeto ("quod") recebido quer a título de comodato ("utendum"), quer a título de depósito ("servandum"), o que já é uma ampliação do conceito original. A regra mais geral encontramos em Gai. 13 ad ed. provinc. D. 47,2,55,1, que conceitua ofurtum usus: "furtum fieri et si quis usum alienae rei in suum lucrum convertat" (ocorre o furto também se alguém converte o uso de coisa alheia em seu benefício). Tal regra é abraçada pela Jurisprudência, e incorporada à própria noção geral de furto, em Paul. 39 ad ed. D. 47,2,1,3: "furtum est contrectatio rei fraudulosa lucri faciendi gratia vel ipsius rei vel etian usus eius possessionisve" (furto é a subtração fraudulenta de uma coisa, para obter lucro, seja da própria coisa, seja também do seu uso ou posse) $)^{22}$

O que aqui se nos depara, e com clareza meridiana, é a transição sucessiva para graus crescentes de abstração, exatamente como teorizou F. Schulz (cf. supra, pág. (h 5). O resultado final é a regula, que corresponde ao que os dialéticos gregos chamavam de Óroj ou k@nèn. Entretanto, F. Schulz repudia a denominação usual de "jurisprudência regular" ("Regularjurisprudenz") para essa busca republicana por princípios, dado que qualquer tendência à formação de regras poderia ser assim rotulada, enquanto o caso romano é fruto da aplicação do método dialético, da dia...resij grega. E preconiza, por tal motivo, o nome "jurisprudência dialética" 23

Percebemos então, que foi na dialética grega e na passagem para a "Regularjurisprudenz" que o Direito Romano encontrou o seu caminho da práxis para a ciência — o que curiosamente não ocorreu no próprio Direito Grego. Não se perca de vista, evidentemente, que apesar de toda essa evolução, os jurisconsultos romanos não perderam jamais a sua perspectiva casuística e pragmática. As definições e conceitos, que não deixaram de surgir, foram, como observa A. Söllner ${ }^{24}$, foram sempre feitas com parcimônia e com muita cautela, e ademais disso sem a menor preocupação

22. Ver ainda Paul. 9 ad Sab. D. 47,2,40; Pomp. 38 ad Q. Muc. D. 47,2,77, pr.; Pomp. 38 ad Q. Muc. D. 13,1,16; G. 3,196. Cf. tb. M. D. Floria Hidalgo, La Casuistica del Furtum en la Jarisprudencia Romana, Madrid, Dykinson, 1991, p. 159-164.

23. History, (cit., supra, nota $\backslash \mathrm{h} 20$ ) p. 67.

24. Einführung in die römische Rechtsgeschichte, 4. ed., München, Beck, 1989, pp. 106 ss. 
com o rigor científico. Muitas vezes as explicações teóricas dadas pelos juristas romanos se limitam a etimologias - não raro falsas - de palavras e expressões de uso corriqueiro. Famosa é, por exemplo, a explicação de Gaio para o significado etimológico da palavra mutuum ("quod ... ex meo tuum fit". Gai. 3,90). Uma erronia tão grosseira dificilmente se acredita que pudesse ter escapado a pessoas notoriamente sábias e esclarecidas como as que formavam o escol da Jurisprudência clássica. Isso só se pode explicar pelo absoluto desinteresse por uma investigação científica dos conceitos: tais etimologias eram aceitas porque cumpriam a sua função mnemônica e didática (lembremo-nos de que Gaio era professor), pouco importando a sua validade científica. Tal era o caráter pragmático da Jurisprudência romana.

\section{Conclusão.}

Nesta brevíssima exposição, tivemos a oportunidade de acompanhar, em linhas muito gerais, o progressivo evolver do pensamento jurisprudencial romano no caminho da abstração e da conceituação genérica de seus institutos - caminho esse que jamais chegou a ser perlustrado até o seu final. O que nos parece relevante é perceber que a riqueza do Direito Romano brotou precisamente dessa maneira viva e dinâmica com que os institutos nasciam e se desenvolviam livremente a partil das ocorrências da casuística, à qual o jurista romano nunca aceilou renunciar. Mesmo com a "Regularjurisprudenz" e a aplicação da dialética de influência grega, a formalização teórica do Direito foi restrita. Um sistema completo eles jamais erigiram. O que se encontra no discurso dos jurisconsultos romanos são apenas algumas poucas estruturas localizadas aqui e ali, ou, no elegante dizer de M. Kaser ${ }^{25}$, ilhas sistemáticas ("systematische Inseln").

Talvez tenha sido essa feliz combinação do espírito prático dos romanos, apenas de leve temperado pela dialética grega, que permitiu à Jurisprudência romana atingir o ápice da arte (termo mais adequado, no caso, do que "ciência") jurídica, campo no qual se mantiveram os romanos inigualados por todos os demais povos da Antigüidade (inclusive os próprios gregos), oferecendo ainda hoje esse rico repositório de idéias e inspiração para o jurista contemporâneo.

São Paulo, junho de 2002.

25. Zur Methode der römischen Rechtsfindung, in Nachrichten der Akademie der Wissenschaften in Göttingen, I-Philologisch-historische Klasse, 1962, v. 2, p. 70; cf. tb. Com M. Bretone, Storia del Dirillo Romano, Laterza, Roma-Bari, 1987 (trad. alemã de Brigitte Galsterer Geschichte des römischen Rechts.s, München, Beck, 1992, p. 205). 